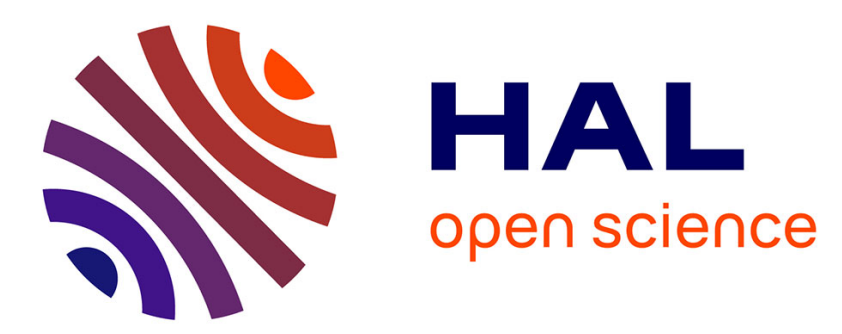

\title{
Dynamics of amphiphilic diblock copolymers at the air-water interface
}

\author{
Antonio Stocco, Klaus Tauer, Stergios Pispas, Reinhard Sigel
}

\section{To cite this version:}

Antonio Stocco, Klaus Tauer, Stergios Pispas, Reinhard Sigel. Dynamics of amphiphilic diblock copolymers at the air-water interface. Journal of Colloid and Interface Science, 2011, 355 (1), pp.172178. hal-00786309

\author{
HAL Id: hal-00786309 \\ https://hal.science/hal-00786309
}

Submitted on 8 Feb 2013

HAL is a multi-disciplinary open access archive for the deposit and dissemination of scientific research documents, whether they are published or not. The documents may come from teaching and research institutions in France or abroad, or from public or private research centers.
L'archive ouverte pluridisciplinaire HAL, est destinée au dépôt et à la diffusion de documents scientifiques de niveau recherche, publiés ou non, émanant des établissements d'enseignement et de recherche français ou étrangers, des laboratoires publics ou privés. 


\title{
Dynamics of amphiphilic diblock copolymers at the air-water interface
}

\author{
Antonio Stocco*1, Klaus Tauer ${ }^{1}$, Stergios Pispas ${ }^{2}$ and Reinhard Sigel ${ }^{3}$
}

\author{
${ }^{1}$ Max Planck Institute of Colloids and Interfaces, 14476 Potsdam-Golm, \\ Germany.*antonio.stocco@mpikg.mpg.de. \\ ${ }^{2}$ Theoretical and Physical Chemistry Institute, National Hellenic Research \\ Foundation, 48 Vass. Constantinou Ave., 11635 Athens, Greece. \\ ${ }^{3}$ Adolphe Merkle Institute, University Fribourg, Switzerland.
}

\begin{abstract}
Two polyisoprene-polyethyleneoxide diblock copolymers with different block length ratios adsorbed to the water surface were investigated by multiple angle of incidence ellipsometry, evanescent wave light scattering, and surface tension experiments. In a semidilute interfacial regime, the transition from a two dimensional to a "mushroom" regime, in which polymer chains form loops and tails in the subphase, was discussed. A diffusion mechanism parallel to the interface was probed by evanescent wave dynamic light scattering. At intermediate concentrations, the interfacial diffusion coefficient $D_{\|}$scales with the surface concentration $\Gamma$, as $D_{\|} \sim \Gamma^{0.77}$ in agreement with the scaling observed for polymer solutions in a semidilute regime. At relatively high concentrations a decreasing of $D_{\|}$is discussed in terms of increasing friction due to interactions between polyisoprene chains.
\end{abstract}

\section{Introduction}

The dynamics of polymer chains at the interface is an important research topic in physics, biology and chemistry. The physical understanding of the diffusion and polymer conformations close to an interface has also a great impact on the study of biological systems such as proteins and membranes and on controlled drug release. Many processes occurring close to a biological membrane could be studied using polymers at liquid-liquid interfaces as model systems. Polymers can adopt at the interface different conformations such as brush -, mushroom -, or pancake - like morphologies [1] and hence, their diffusion mechanism differs significantly from that in solution. In dilute and concentrate solution the dynamics of flexible polymers is well described by the Rouse and the Reptation model, respectively [2].

Furthermore, liquid interfaces are frequently the loci for chemical reactions. In this view, the interfacial region might be considered almost as 2D-reactor with width of only a few nanometers where reactions are governed by the particular interfacial 
properties ( $\mathrm{pH}$, lyophilic - lyophobic interactions, electrical charge, etc) that significantly differ from the bulk values [3].

Up to date, macromolecules at the air-water interface were investigated extensively mainly regarding adsorption kinetics and chain conformation transitions [4, 5, 6]. The kinetics of adsorption from the bulk phase to the interface could be followed, for instance, by tensiometry and ellipsometry [6, 7]. The surface tension changes as a result of a diffusion process followed by conformational reorganizations at the interface [6] and the resulting layer is usually referred as "Gibbs layer".

The knowledge of the interface concentration is an essential parameter for studies of the conformation of adsorbed polymers. This concentration is usually controlled by varying the interfacial area in a Langmuir trough, in which a non-aqueous polymer solution is spread on the top of the water surface. These layers are known as "Langmuir layers" and their structural conformations have been studied by tensiometry, rheology, neutron/x-ray reflectivity, capillary wave scattering, electrocapillary waves and oscillating barrier experiments [8, 9, 10, 11, 12, 13, 14, 15].

What remained almost unexplored, due to experimental limitations, is the inplane diffusion at the air-water interface. Only very few techniques are capable to measure the mobility of polymer chains at the interface. Among them, fluorescence recovery after photobleaching (FRAP) and single molecule fluorescence imaging were used to study the interfacial diffusion of phospholipids [16, 17]. For non-fluorescing adsorbed molecules, evanescent wave light scattering is a proper tool [18, 19, 20].

The structure and dynamics of polymers attached to an interface are different compared to the bulk [21]. Considering the case of amphiphilic diblock copolymers, different regimes and phases can be encountered in the solution when the concentration is changed. In these different states the polymer changes both the conformation and the diffusion mechanism, which can be usually expressed by a different scaling law [2]. In a common solvent for the two blocks, a micro phase separation is encountered above a characteristic concentration which affects several diffusion and relaxation mechanisms [22, 23, 24, 25, 26, 27]. In a selective solvent, on the other hand, polymer micelles are formed with a core built up by the insoluble block. The diffusion of polymeric micelles is similar to colloidal particles, although the friction is significantly altered by the polymer corona formed by the soluble block segments [28, 29].

Here, we investigated two amphiphilic neutral biocompatible diblock copolymers composed of polyisoprene and polyethyleneoxide at the air-water interface. In order to study the polymer dynamics in different regimes, we prepared "Gibbs layers" by changing quasi-statically the concentration of the block copolymers in the aqueous phase. The experimental system is well defined and consists only of block copolymers 
distributed between the bulk water and the vapor- water interface.

The paper is organized as follow: Sec. 2 describes the chemical system and the methods used for the interfacial characterization; Sec. 3.1 recalls the properties of the solutions in the range of concentration considered here. After presenting the ellipsometric results in Sec. 3.2, interfacial regimes (Sec. 3.3) and the corresponding dynamics (Sec. 3.3) are discussed before the Conclusions section (Sec. 4).

\section{Material and Methods}

\subsection{Amphiphilic diblock copolymers}

Polyisoprene-polyethyleneoxide (PI-PEO) diblock copolymers were synthesized by anionic polymerization using high vacuum techniques, as described elsewhere [30, 31]. Two block copolymers, characterized by different degrees of polymerization $N$, were used: $\mathrm{PI}_{111} \mathrm{PEO}_{201}$ and $\mathrm{PI}_{88} \mathrm{PEO}_{334}$. For those systems, in Tab. 1 the values of molecular weight $\mathrm{M}_{w}$ and polydispersity $\mathrm{M}_{w} / \mathrm{M}_{n}$ (obtained by GPC analysis), and the weight percent of polyisoprene (evaluated by NMR) are reported. The sizes of the hydrophobic (PI) and hydrophilic (PEO) blocks are different for the two copolymers. Tab. 1 shows the Flory radii for PEO and PI of $\mathrm{PI}_{111} \mathrm{PEO}_{201}$ and $\mathrm{PI}_{88} \mathrm{PEO}_{334}\left(R_{F}=N^{3 / 5} \cdot a\right.$, where $a$ is the "monomer size" of the block. $a$ was considered as contour length of the segments: $a_{P E O}=0.36 \mathrm{~nm}$ and $a_{P I}=0.50 \mathrm{~nm}$ ). Note that the two blocks of $\mathrm{PI}_{111} \mathrm{PEO}_{201}$ have almost identical Flory radii, whereas $\mathrm{PEO}$ represents the predominant block in $\mathrm{PI}_{88} \mathrm{PEO}_{334}$.

The hydrophobic character of $\mathrm{PI}_{111} \mathrm{PEO}_{201}$ and $\mathrm{PI}_{88} \mathrm{PEO}_{334}$ can be related to the ratio between the Flory radii $r=R_{F, P I} / R_{F, P E O}$ [4].

As one can read in Tab. 1. $\mathrm{PI}_{111} \mathrm{PEO}_{201}$ is more hydrophobic than $\mathrm{PI}_{88} \mathrm{PEO}_{334}$ and also shorter in size if the nominal length of the blocks in the all-trans configuration are considered $\left(L_{A T}=\sum N_{i} \cdot a_{i}\right)$.

\begin{tabular}{|c|c|c|c|c|c|c|c|}
\hline name & $\mathrm{M}_{w}$ & $\mathrm{M}_{w} / \mathrm{M}_{n}$ & $\mathrm{PI}(\mathrm{wt} . \%)$ & $L_{A T}(\mathrm{~nm})$ & $R_{F, P I}(\mathrm{~nm})$ & $R_{F, P E O}(\mathrm{~nm})$ & $r$ \\
\hline $\mathrm{PI}_{111} \mathrm{PEO}_{201}$ & 16400 & 1.08 & 46 & 127 & 8.4 & 8.7 & 0.97 \\
$\mathrm{PI}_{88} \mathrm{PEO}_{334}$ & 20700 & 1.03 & 29 & 164 & 7.3 & 11.8 & 0.61 \\
\hline
\end{tabular}

Table 1: Molecular weight $\mathrm{M}_{w}$, polydispersity quantified by $\mathrm{M}_{w} / \mathrm{M}_{n}$, weight percent of PI in the diblock copolymer, nominal length $L_{A T}$ of the diblock copolymer in the all-trans configuration, Flory radii of PI and PEO blocks and ratio $r$ between the Flory radii as a measure of hydrophobicity. 


\subsection{Polymer solutions}

We prepared aqueous polymer solutions at different concentrations for $\mathrm{PI}_{111} \mathrm{PEO}_{201}$ and $\mathrm{PI}_{88} \mathrm{PEO}_{334} \cdot \mathrm{PI}_{88} \mathrm{PEO}_{334}$ is directly soluble in water over a wide range of concentration, and several solutions from 0.001 to $2000 \mathrm{mg} \mathrm{L}^{-1}$ were easily prepared by dissolving the polymer into the water.

$\mathrm{PI}_{111} \mathrm{PEO}_{201}$, being more hydrophobic, is not directly soluble in water. For this polymer, a solution with a concentration $c=500 \mathrm{mg} \mathrm{L}^{-1}$ in water (in $20 \mathrm{~mL}$ volume) was obtained by dissolving the sample first in $2 \mathrm{~mL}$ of tetrahydrofuran (THF) and then adding dropwise the water under stirring. Before application the THF was removed by thermal treatment at $60^{\circ} \mathrm{C}$ for 8 hours inside an oven. Solutions with lower concentrations were obtained by dilution of the most concentrated stock solution using high purity water from a Milli-Q-RG ultrafiltration system.

Standard static (SLS) and dynamic (DLS) light scattering of aqueous $\mathrm{PI}_{111} \mathrm{PEO}_{201}$ and $\mathrm{PI}_{88} \mathrm{PEO}_{334}$ solutions were carried out to characterize the aggregation state in the bulk phase. For both polymers, we measured a refractive index increment $\partial n / \partial c=0.157 \mathrm{~mL} \mathrm{~g}^{-1}$ (by an interferometer NFT, Gottingen, Germany). Spherical shaped aggregates of hydrodynamic radius $R_{h}=35 \mathrm{~nm}$ (bulk diffusion coefficient $\left.D_{0}=6.1 \mu \mathrm{m}^{2} \mathrm{~s}^{-1}\right)$ for $\mathrm{PI}_{111} \mathrm{PEO}_{201}$ and $R_{h}=46 \mathrm{~nm}\left(D_{0}=4.7 \mu \mathrm{m}^{2} \mathrm{~s}^{-1}\right)$ for $\mathrm{PI}_{88} \mathrm{PEO}_{334}$ were detected.

For surface tension measurements, solutions were prepared separately by dilution as described above.

For ellipsometric and scattering measurements, instead, we added a polymer solution into a cylindrical cell (diameter $7.5 \mathrm{~cm}$, interfacial area $A=0.0056 \mathrm{~m}^{2}$, total volume $2 V=0.25 \mathrm{~L}$ ), which was half filled with pure water. The pure water surface was accurately cleaned. The concentration in the system is varied adding in different steps a volume of $50 \mu \mathrm{L}$ of a more and more concentrated aqueous polymer solution by means of a microsyringe (Gastight, Hamilton). The volume of the solution is added dropwise on the top of the surface. For each bulk concentration, at least 14 hours are allowed to elapse before the first ellipsometric and scattering measurements. These measurements were repeated after additional 12 hours, without noting significant differences.

\subsection{Tensiometry}

The air-water interfacial tension $\gamma$ of the diblock copolymer solution in water was determined by the Wilhelmy plate method with a K12 tensiometer (Kruss, Germany). $\mathrm{PI}_{111} \mathrm{PEO}_{201}$ and $\mathrm{PI}_{88} \mathrm{PEO}_{334}$ solutions of different concentrations were separately prepared and measured. The $\gamma$ values were monitored during a time of $4 \times 10^{4}$ sec- 
onds, in which $\gamma$ eventually reached a plateau value. For two concentrations the results were cross checked with the pendant drop method, where the surface tension can be measured by imaging analysis of a drop deformed under gravity. The values found by the two different methods were in good agreement.

\subsection{Ellipsometry}

Recently we have described a new apparatus which implements multiple angle of incidence ellipsometry and evanescent light scattering together [32, 33, 34]. A cylindrical cell geometry is used, and allows ellipsometric scans from any incident angle $\varphi$ above or below the interface being the incident beam always perpendicular to the cell's wall.

The ratio of the reflectivities $r_{p}$ and $r_{s}$ is related to the two real ellipsometric parameters $\Psi$ and $\Delta$ by [35]:

$$
\frac{r_{p}}{r_{s}}=\tan \Psi \cdot \exp (i \Delta)
$$

Data are analyzed in the framework of a perturbation theory [36], which describes the deviation of the ellipsometric coefficient from a coefficient $r_{p, 0} / r_{s, 0}$ for a sharp step-like profile:

$$
\frac{r_{p}}{r_{s}}=\frac{r_{p, 0}}{r_{s, 0}}-\frac{2 i Q_{1}}{r_{s, 0}\left(Q_{1}+Q_{2}\right)^{2}} \frac{K^{2}}{n_{1}^{2} n_{2}^{2}} J_{1} .
$$

Where $Q_{i}=2 \pi /\left(n_{i} \lambda\right) \cdot \cos \varphi_{i}, \lambda=633 \mathrm{~nm}, K=2 \pi n_{1} / \lambda \cdot \sin \varphi_{1}$ (where the Snell's law $n_{1} \sin \varphi_{1}=n_{2} \sin \varphi_{2}$ describes the relation between the angles $\varphi_{i}$ in the media of refractive index $n_{i}=\left(\epsilon_{i}\right)^{1 / 2}$ ) and the first order invariant:

$$
J_{1}=\int_{-\infty}^{+\infty} \frac{\left(\epsilon_{1}-\epsilon_{m}(z)\right)\left(\epsilon_{m}(z)-\epsilon_{2}\right)}{\epsilon_{m}(z)} \mathrm{d} z,
$$

combines the extension of the interfacial region (coordinate $z$ normal to the interface) and the profile of the dielectric constant $\epsilon_{m}(z)=\left(n_{m}(z)\right)^{2}$ in a single parameter.

All the ellipsometric measurements presented here are performed from the waterside (below the interface). We scanned the incident angle close to the lower Brewster angle $\left(=\arctan \left(1 / n_{\mathrm{H}_{2} \mathrm{O}}\right) \approx 36.9 \mathrm{deg}\right)$ in fine steps of 0.03 degree. Refractive index of water $n_{\mathrm{H}_{2} \mathrm{O}}=1.333$

\subsection{Evanescent light scattering}

Light scattering at the surface is performed through the water phase under evanescent illumination, choosing the incident angle $\varphi$ larger than the critical angle $\varphi_{0}$. 
For liquid interfaces, this geometry was recently described by the authors, and experimental details can be found in the reference [33]. In this work, the light was always polarized in the direction parallel to the reflection plane (p-polarization). Static scattered intensity $I_{s}$ was measured in a wide range $30<\varphi(\mathrm{deg})<70$ of the incident angle, keeping the scattered angle $\psi=20 \mathrm{deg}$ fixed [33].

Surface autocorrelation functions $g_{1}\left(q_{\|}, t\right)$ were measured varying the parallel component of the scattering vector

$$
q_{\|}=n_{1} k_{0}[\sin (\varphi)-\sin (\psi)]
$$

(where $k_{0}=9.926 \mu \mathrm{m}^{-1}$ ) in a angular range $5<\psi(\mathrm{deg})<55$. The geometry was restricted to the case where the scattered light is detected in the reflection plane. The tilt option of the experimental apparatus for an independet variation of $q_{\|}$and the perpedicular component $q_{\perp}$ of the scattering vector was not used. For polymer adsorbed to the liquid interface with an small size extension compared to $\lambda$ the effect of the motion perpendicular to the interface can be neglected, and thus the change in $q_{\perp}$ upon a variation of $q_{\|}$has no effect. The incident angle $\varphi=65 \mathrm{deg}$ is chosen significantly above the critical angle $\varphi_{0}=\arcsin \left(1 / n_{\mathrm{H}_{2} \mathrm{O}}\right) \approx 48.6$ deg of total internal reflection in order to have a high surface sensitivity, i. e. a small penetration depth $d_{p} \approx 150 \mathrm{~nm}$ of the evanescent wave.

\section{Results and discussion}

In the first section of the this part, the properties of polymer solutions as a function of the bulk concentration will be described. Whereas in the following sections, the investigation of equilibrium or pseudo-equilibrium states of adsorbed polymers at the interface will be presented. For each bulk concentration studied, these interfacial states are reached after completing the adsorption from the bulk to the interface.

\subsection{Brief summary of the solution behavior}

The PI-PEO copolymers were investigated in dilute aqueous solutions by the pyrene fluorescence method, interfacial tension measurements, and light scattering over a large concentration range $\left(0.1<c<2000 \mathrm{mg} \mathrm{L}^{-1}\right)$. Fluorescence measurements indicated a structural transition at around $10 \mathrm{mg} \mathrm{L}^{-1}$, whereas light scattering detected the presence of aggregates over the whole concentration range. The interfacial tension liquid - vapor decreases smoothly over the whole concentration range without any sign of reaching a saturation. At higher concentrations larger aggregates have

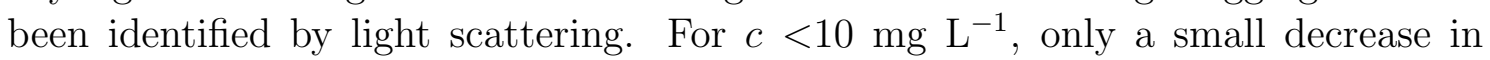
the total molecular weight of the aggregates in solution is found. This decrease in 
total molecular weight is considered to reflect a decrease in the aggregation number [37, 38.

\subsection{Surface concentration by Ellipsometry}

Due to their amphiphilic characters, diblock copolymers PI-PEO will tend to adsorb onto the air-water interface modifying the optical properties of the interfacial region. Accurate ellipsometric experiments were performed in order to evaluate the change of the dielectric constant profile and estimate the surface concentration of the adsorbed polymer. The ellipsometric parameters $\tan (\Psi)$ and $\Delta$ around the Brewster angle $\varphi_{B}$ are shown in Fig. 1. $\tan (\Psi)$ and $\Delta$ changed significantly just around $\varphi_{B}$ where the sensitivity to the interfacial profile is maximum. Qualitatively, the minimum of $\tan (\Psi)$ and the slope of $\Delta$ at $\varphi_{B}$ can be related to the adsorption of the polymer at the interface. Increasing the bulk polymer concentration, we observed that the changes of the ellipsometric parameters are higher for $\mathrm{PI}_{111} \mathrm{PEO}_{201}$ (more hydrophobic) than for $\mathrm{PI}_{88} \mathrm{PEO}_{334}$.

Ellipsometric data were fitted in the framework of the perturbation theory; the fitting parameter $J_{1}$ is plotted as a function of the bulk concentration in Fig. $2 \mathrm{a}$. For $\mathrm{PI}_{111} \mathrm{PEO}_{201}, J_{1}$ decreased significantly at around $0.1 \mathrm{mg} \mathrm{L} \mathrm{L}^{-1}$, then it remained approximately constant until $10 \mathrm{mg} \mathrm{L}^{-1}$ before decreasing again. For $\mathrm{PI}_{88} \mathrm{PEO}_{334}, J_{1}$ varied less than for $\mathrm{PI}_{111} \mathrm{PEO}_{201}$, and it changes almost linearly with the logarithm of the concentration. The first order invariant $J_{1}$ provides an estimation of the change of the interfacial profile without the need of any assumption on the dielectric constant profile and the extension of the interfacial region. In general, for very thin interfacial layers the two latter properties are coupled and it is not possible to determine the two quantities separately. In this limit, the first order invariant $J_{1}$ is related to the zeroth moment of the dielectric constant profile $\Gamma_{0}=\int_{0}^{\infty} \epsilon_{m}(z)-\epsilon_{\mathrm{H}_{2} \mathrm{O}} \mathrm{d} z$ by [36, 39]:

$$
J_{1}=\frac{\epsilon_{A i r}-\epsilon_{\mathrm{H}_{2} \mathrm{O}}}{\epsilon_{\mathrm{H}_{2} \mathrm{O}}} \Gamma_{0}
$$

The surface concentration can be estimated as $\Gamma=\Gamma_{0}\left(\frac{\partial \epsilon}{\partial c}\right)^{-1}$ (where the dielectric constant increment $\frac{\partial \epsilon}{\partial c}=\frac{\partial n^{2}}{\partial c}=2 \mathrm{n}_{\mathrm{H}_{2} \mathrm{O}} \frac{\partial n}{\partial c}=0.42 \mathrm{~mL} \mathrm{~g}^{-1}$ ) subtracting from $J_{1}$ the value of $J_{A W}=-0.119 \mathrm{~nm}$ for bare air-water interface [34].

The results are displayed in Fig. 2b. Now, the experimental surface concentration can be compared with the theoretical values $\Gamma=c V / A$ for complete adsorption, thus assuming that the added polymer molecules are entirely adsorbed. For $\mathrm{PI}_{111} \mathrm{PEO}_{201}$ and bulk concentration lower than $c^{*}=0.3 \mathrm{mg} \mathrm{L}^{-1}$, the surface concentration evaluated by the ellipsometric analysis goes parallel with the theoretical line but the 

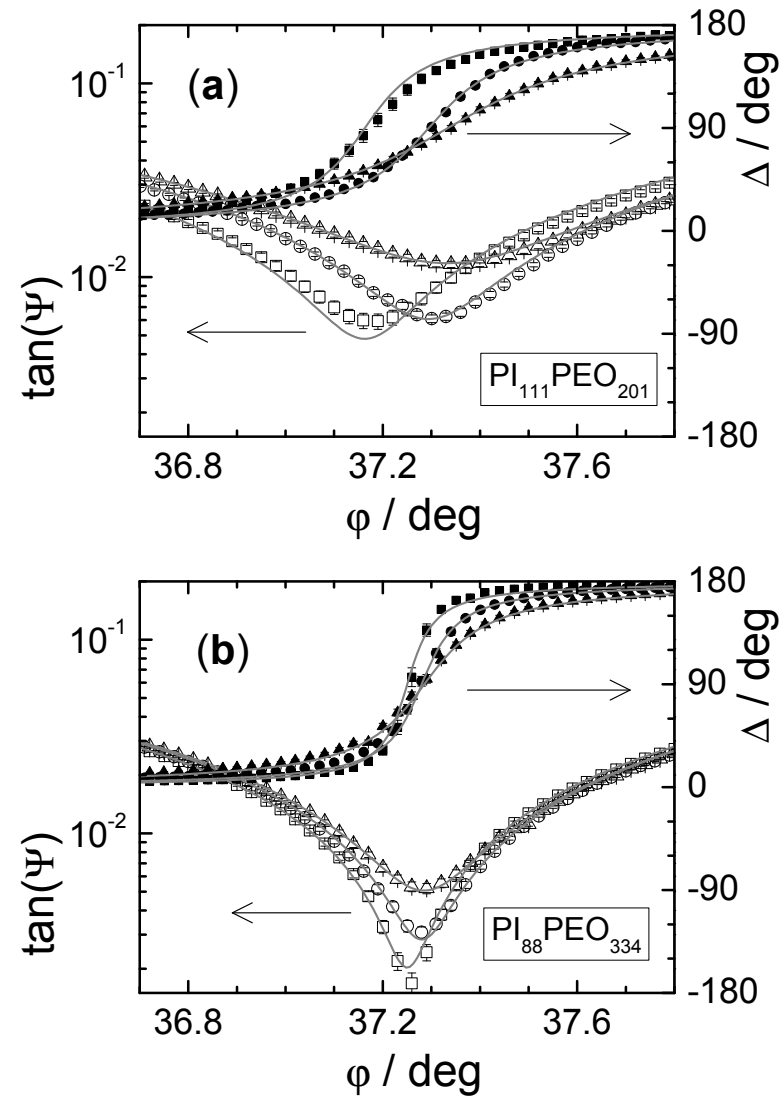

Figure 1: a) Ellipsometric parameters $\tan (\Psi)$ and $\Delta$ measured through the water

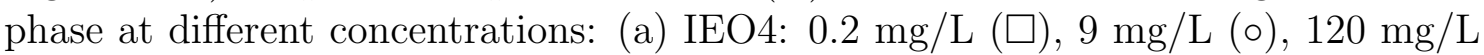
$(\triangle)$; (b) IOE2: $0 \mathrm{mg} / \mathrm{L}(\square) ; 5 \mathrm{mg} / \mathrm{L}(\circ) ; 200 \mathrm{mg} / \mathrm{L}(\triangle)$. Gray lines are simultanous fits to $\tan (\Psi)$ and $\Delta$ data. 
values are expectedly slightly lower indicating that polymer (or micelle) adsorption at the interface is not complete. Above the latter concentration, $\Gamma<<c V / A$, meaning that the most of the added polymer prefers to diffuse into the bulk instead of adsorbing at the interface. For $\mathrm{PI}_{88} \mathrm{PEO}_{334}$ instead the surface concentration varies almost linearly with the logarithm of the bulk concentration (except one outlier) remaining however always below the complete adsorption line $\Gamma=c V / A$.

At the highest bulk concentrations, the surface concentration changes up to $4 \mathrm{mg}$ $\mathrm{m}^{-2}$ for $\mathrm{PI}_{111} \mathrm{PEO}_{201}$ and $2 \mathrm{mg} \mathrm{m}{ }^{-2}$ for $\mathrm{PI}_{88} \mathrm{PEO}_{334}$. These changes can be due to either an increasing layer thickness or a denser polymer structure.

Note that ellipsometric data corresponding to $\Gamma<0.2 \mathrm{mg} \mathrm{m}^{-2}$ do not deviate significantly from the data for the pure air-water interface, showing the same $J_{1}$ values within experimental accuracy. Furthermore, in the present analysis, anisotropy of the interfacial layer (accounted for the pure air-water interface) was also not taken into account [34]. For these two reasons, data corresponding to $\Gamma<0.2 \mathrm{mg} \mathrm{m}^{-2}$ should not be considered in the following discussions.

In a log-log plot the adsorbed amounts change for both block copolymers in the reliable concentration range linearly with concentration (Fig. 2b). The experimental data points reflect the different block copolymer composition quite reasonably as the more hydrophobic molecules $\left(\mathrm{PI}_{111} \mathrm{PEO}_{201}\right)$ adsorb in greater amounts.

\subsection{Interfacial regimes}

In order to investigate interfacial regimes of diblock copolymers adsorbed onto the air-water interface, in this section surface tension and surface static light scattering measurements are described together. In the end of the section, a discussion on the transition surface concentrations will be also presented.

Polymer adsorption at the air-water interface causes a decrease of the interfacial tension from $\gamma_{0}=$ ca $72 \mathrm{mN} \mathrm{m}^{-1}$, which is the value of the pure water. The difference $\gamma_{0}-\gamma$ is defined as surface pressure $\Pi$ that increases with the adsorbed amount of organic matter and reaches a constant value if the surface is saturated. Fig. 3 a compares the surface pressure data for the diblock copolymers with that of a PEO-PPO-PEO (where PPO is polypropyleneoxide) triblock copolymer and a low molecular weight nonionic surfactant. Both PI-PEO diblock copolymers show over the whole concentration range an almost linear increase of the surface pressure. For $\mathrm{PI}_{88} \mathrm{PEO}_{334}$ one can discuss a small step in the surface pressure-concentration curve between 3 and $10 \mathrm{mg} \mathrm{L}^{-1}$.

In contrast, the low molecular weight nonionic surfactant $\mathrm{C}_{13} \mathrm{PEO}_{8}$ (Genapol X089, Clariant, Germany) exhibits a sharp transition point at a concentration of about $60 \mathrm{mg} \mathrm{\textrm {L } ^ { - 1 }}$ above which the surface pressure remains constant $\left(\Pi=45 \mathrm{mN} \mathrm{m}^{-1}\right)$. 


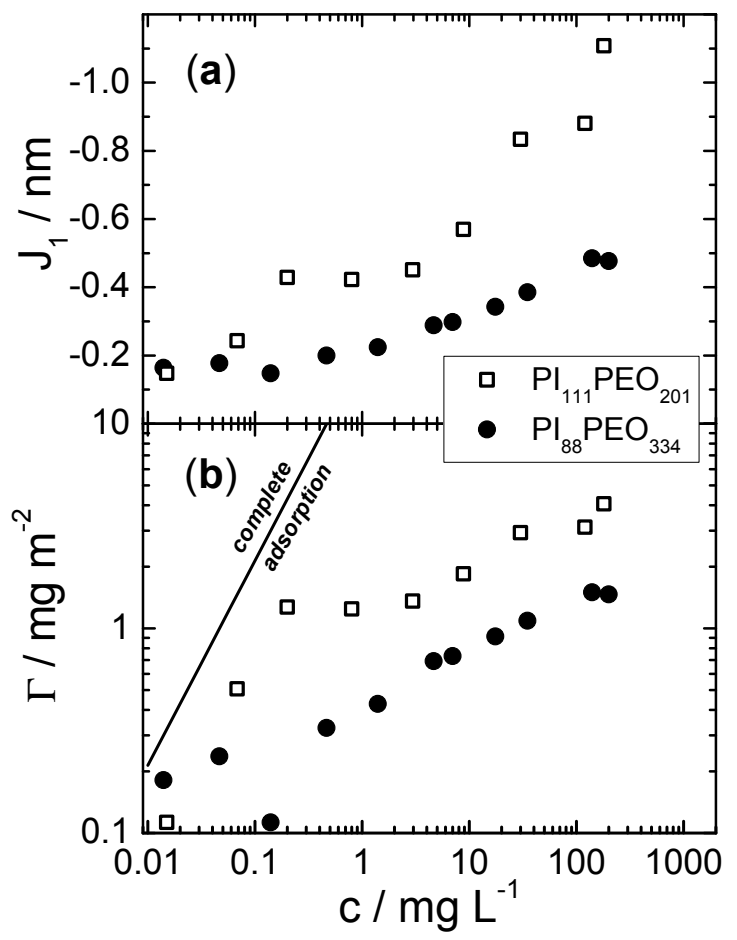

Figure 2: a) First order invariant $J_{1}$ as a function of polymer concentration of $\mathrm{PI}_{111} \mathrm{PEO}_{201}(\square)$ and $\mathrm{PI}_{88} \mathrm{PEO}_{334}(\bullet)$. b) Surface concentration $\Gamma$ calculated form the ellipsometric analysis as a function of polymer concentration of $\mathrm{PI}_{111} \mathrm{PEO}_{201}(\square)$ and $\mathrm{PI}_{88} \mathrm{PEO}_{334}(\bullet)$. The solid line represents the surface concentration calculated assuming that all polymer adsorb onto the interface. 
This behavior is the clear signature of a critical micelle concentration (CMC) and a saturated surface. For surfactants, in fact, a thermodynamic equilibrium between interface and bulk allows to interpret interfacial transitions in terms of phase transition happening in solution; and for bulk concentrations above the CMC, micellar aggregates in solution are in equilibrium with the free surfactants adsorbed at the interface.

The surface pressure data of block copolymers show a completely different behavior suggesting an increasing surface concentration over the whole concentration range. This is particularly evident for a PEO-PPO-PEO system (Synperionic F68, $\mathrm{M}_{w}=8350$, Fluka, Germany [4]). At this point, two main differences between the behavior of low molecular weight surfactants and high molecular weight amphiphilic polymers should be pointed out. Firstly, being the polymer adsorption at the water surface irreversible no equilibrium exists between bulk and interface [40]. Consequently, no CMC can be observed from surface pressure measurements, in particular when the surface concentration $\Gamma$ shows a continuous increase.

Moreover, for copolymers in general one should consider the influence of the polydispersity as discussed in [41]. Even a polydispersity index of 1.03 means that only about $10 \%$ of the molecules have the nominal chain length and hence, quite a mixture of molecules with different surface activity interact in solution and compete for the interface. In this sense, fractionation can happen due to the different adsorption properties and solubilities of the molecules in dependence on the ratio of the length of the hydrophobic and hydrophilic blocks. As the hydrophobic block is the same for $\mathrm{PI}_{111} \mathrm{PEO}_{201}$ and $\mathrm{PI}_{88} \mathrm{PEO}_{334}$ surface tension measurements are unable to differentiate between both block copolymers.

The surface static scattered intensity $I_{s}$ ( Fig. 3b, cf. Sec. 2.5) shows for both block copolymers a different concentration behavior [33] comparing to surface pressure data. For $\mathrm{PI}_{111} \mathrm{PEO}_{201}, I_{s}$ decreases slightly at low concentrations passing through a shallow minimum at around $3 \mathrm{mg} \mathrm{L}^{-1}$, before it increases significantly at high concentrations. A sharp maximum is observed at an intermediate concentration $\left(5 \mathrm{mg} \mathrm{L}^{-1}\right)$ for $\mathrm{PI}_{88} \mathrm{PEO}_{334}$.

Surface tension measurements provide information on the surface energy and could help understand changes in phases and regimes at the water surface. Evanescent wave light scattering probes concentration and density fluctuations at the interface. These fluctuations are dominated by thermally excited capillary waves only at very small scattering vector: $q_{\|}<1 \mu \mathrm{m}^{-1}$, and very low concentration: $c<0.2 \mathrm{mg}$ $\mathrm{L}^{-1}[33,43]$. Whereas, in the $q_{\|}$-range considered here they reflect the dynamics of the polymer close to the interface [33].

For $\mathrm{PI}_{88} \mathrm{PEO}_{334}$ in particular, the change of $I_{s}$ at intermediate concentration re- 


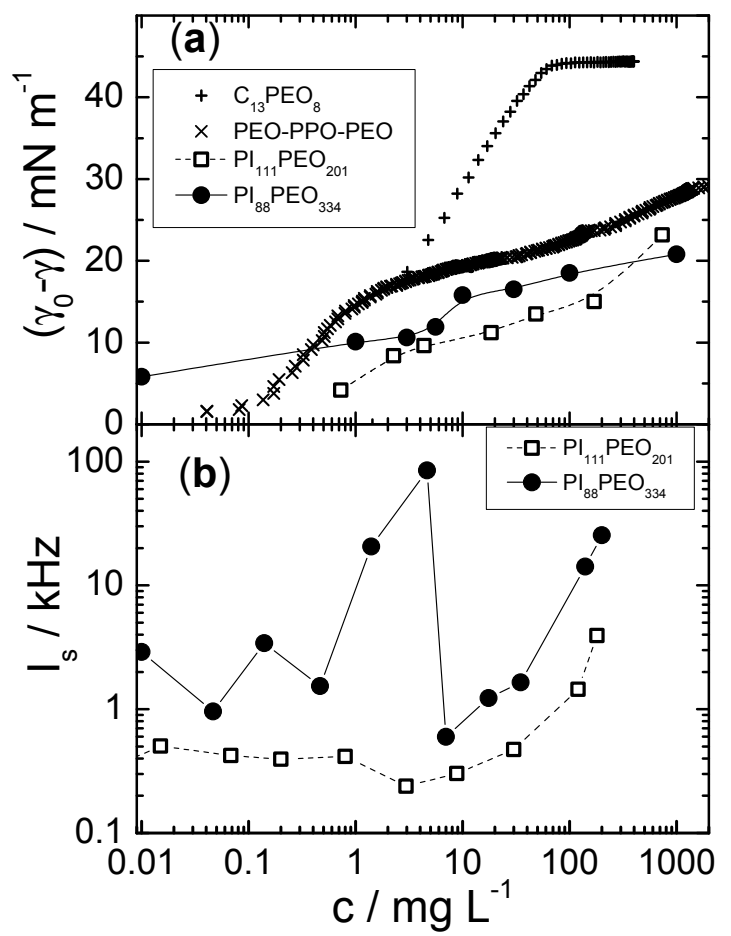

Figure 3: a) Surface pressure $\gamma_{0}-\gamma$ measured at different polymer concentrations by Wilhelmy plate method for $\mathrm{PI}_{111} \mathrm{PEO}_{201}(\square), \mathrm{PI}_{88} \mathrm{PEO}_{334}(\bullet)$ and $\mathrm{C}_{1} 3 \mathrm{PEO}_{8}$ (Genapol X089, Clariant, Germany) for comparison. b) Average surface static scattered intensity as a function of polymer concentration of $\mathrm{PI}_{111} \mathrm{PEO}_{201}(\square)$ and $\mathrm{PI}_{88} \mathrm{PEO}_{334}(\bullet)$. Lines can be used to guide the viewers eyes.

sembles a second order or a weak first order phase transition [24, 25], in agreement with the change observed in surface pressure data (Fig. 3a); i.e. both $I_{s}$ and the derivative of the surface pressure $-(\partial \gamma / \partial \ln c)$ show maximum values at around 1-10 $\mathrm{mg} \mathrm{L} \mathrm{L}^{-1}$.

We can now compare our experimental observations with an interfacial transition reported for PEO-PPO-PEO copolymers. For these multiblock systems, a structural transition at the air-water interface at around $\mathrm{c}=0.1-1 \mathrm{mg} \mathrm{L}^{-1}$ was associated to the formation of a compact interfacial polymer layer with $\mathrm{PEO}$ chains extending into the water subphase or folding around the hydrophobic blocks [10, 44]. The corresponding surface concentration $\Gamma=0.4 \mathrm{mg} \mathrm{m}^{-2}[1]$ and surface pressure $\Pi=\gamma_{0}-\gamma=$ $10-20 \mathrm{mN} \mathrm{m}^{-1}$ for this transition were also reported [9].

In accordance with published data [4, 9, 19], we can interpret the changes for $\mathrm{PI}_{88} \mathrm{PEO}_{334}$ at around $c=1-10 \mathrm{mg} \mathrm{L}^{-1}$ and $\gamma_{0}-\gamma=10-15 \mathrm{mN} \mathrm{m}^{-1}$ as the tran- 
sition from a $2 \mathrm{D}$ to a $3 \mathrm{D}$ structure with $\mathrm{PEO}$ chains protruded into the water phase. This scenario is indicated by the abrupt change of the surface scattered intensity and by a smooth change of the ellipsometric parameter $J_{1}$ which corresponds to $\Gamma=$ ca $0.7 \mathrm{mg} \mathrm{m}^{-2}$ (see Fig. 2b).

A critical surface concentration $\Gamma_{1}$ for this transition can be estimated considering a close packed concentration of cylindrical ("pancake") structure of height $a: \Gamma_{1}=$ $\rho \pi a /(4 \cdot \sin (60))$. Where $a$ represents the monomer size of the block which determines this transition, the factor $\sin (60)$ arises from the assumption of an hexagonal close-packed lattice and $\rho$ is the density (assumed as in the bulk). $\Gamma_{1}=$ ca $0.4 \mathrm{mg}$ $\mathrm{m}^{-2}$ can be calculated supposing either PI or PEO as the determining block for this transition.

This $\Gamma_{1}$ value is quite close to $\Gamma=$ ca $0.7 \mathrm{mg} \mathrm{m}^{-2}$ deduced from the experimental data of Fig. $3 \mathrm{~b}$ for this transition.

Nonetheless, considering the surface pressure data (Fig. 3a), in the $2 \mathrm{D}$ regime the polymer "pancakes" would interact strongly, even before overlapping, as indicated by $\Pi \approx 7 \mathrm{mN} \mathrm{m}^{-1}$. Differently form a "pancakes"-regime, one can imagine a scenario in which the polymer adopt a loose network structure as for self-similar adsorbed layer (SSAL) [46]. Hence, the transition observed at $\Gamma=$ ca $0.7 \mathrm{mg} \mathrm{m}^{-2}$ could be interpreted as the transition to a more extended 3D structure occurring when the chains are already overlapped [46, 14]. Aguie-Beghin et al. assumed that 2D conformations can be estimated by the two-dimensional Flory's radius $R_{F 2}$ for multiblock polymers at the gas-liquid interface [42]. For $\mathrm{PI}_{88} \mathrm{PEO}_{334}, R_{F 2, P I}=N_{P I}^{3 / 4} \cdot a=14 \mathrm{~nm}$ and $R_{F 2, P E O}=28 \mathrm{~nm}$ (see Sec. 2.1). An overlap concentration for each block can be estimates as $\Gamma_{P, 1} \cong \mathrm{M}_{w} /\left(\mathrm{N}_{A} \cdot \bar{R}_{F 2, i}^{2}\right)=0.17 \mathrm{mg} \mathrm{m}^{-2}$ for PI and $0.04 \mathrm{mg} \mathrm{m}^{-2}$ for PEO (where $\mathrm{N}_{A}$ is the Avogadro's number) [42]. Therefore, PEO chains might overlap for $\Gamma>0.04 \mathrm{mg} \mathrm{m}^{-2}$ forming a SSAL; by increasing concentration the interfacial layer would start to stretch in the subphase forming a "mushroom" like structure at $\Gamma=$ ca $0.7 \mathrm{mg} \mathrm{m}^{-2}$.

The discussed changes should be viewed as a transition between regimes and by no means as an indication of a second order phase transition.

Going back to the scattered in intensity in Fig. 3b, in a similar range of the bulk concentration such a transition is not observed for $\mathrm{PI}_{111} \mathrm{PEO}_{201}$. This block copolymer has a lower molecular weight and is more hydrophobic than $\mathrm{PI}_{88} \mathrm{PEO}_{334}$ and, hence, it can adsorb and rearrange more easily. In order to compare the interfacial properties of both polymers, the surface concentration is more suited than the bulk concentration. Such a comparison will be presented in the next section where experimental data for the interfacial diffusion in different regimes will be considered as a function of the surface concentration. 


\subsection{Interfacial diffusion}

Fig. 4 shows surface autocorrelation functions $g_{1}(t)$ for $\mathrm{PI}_{111} \mathrm{PEO}_{201}$ and $\mathrm{PI}_{88} \mathrm{PEO}_{334}$ at a given bulk concentration for different scattering vectors (cf. Sec. 2.5). Autocorrelation functions measured under evanescent illumination were fitted using the CONTIN method [45, and for each $g_{1}(t)$ a characteristic relaxation time $\tau$ was extracted. In the insets of Fig. 4, $\tau^{-1}$ is plotted as a function of the square of the parallel component of the scattering vector $q_{\|}$(equation 4); the scaling between $\tau^{-1}$ and $q_{\|}^{2}$ points to a diffusion mechanism parallel to the interfacial plane. Hence, an apparent interfacial diffusion coefficient $D_{\|}=\tau^{-1} q_{\|}^{-2}$ is accessible for each bulk concentration (Fig. 5a). Note there is no diffusion perpendicular to the interface, $D_{\perp}=0$. In fact, there is no back and forth exchange of polymer between the interface and the bulk water as the polymer adsorption is irreversible.

For $\mathrm{PI}_{111} \mathrm{PEO}_{201}, D_{\|}$reaches at a concentration of about $3 \mathrm{mg} \mathrm{L}^{-1}$ a maximum, where the static intensity is minimum, and decreases at higher concentrations following a trend opposite to the derivative of the surface pressure (see Fig. 3b). For $\mathrm{PI}_{88} \mathrm{PEO}_{334}, D_{\|}$reaches a minimum at about $1 \mathrm{mg} \mathrm{L}{ }^{-1}$, where the static intensity is maximum, and increases at higher concentrations following also a trend opposite to the derivative of the surface pressure (see Fig. 3b).

These experimental data reveal that evanescent wave static and dynamic light scattering and surface tension measurements are interrelated and should be discussed accounting the surface concentrations evaluated by ellipsometry.

Considering both block copolymers together, plotting $D_{\|}$as a function of the surface concentration evaluated by ellipsometry (in the range from 0.2 to $6 \mathrm{mg}$ $\mathrm{m}^{-2}$, Fig. 5b), allows to distinguish three different regimes: a) $\Gamma<0.4 \mathrm{mg} \mathrm{m}^{-2}$ b) $0.4<\Gamma<$ ca $1 \mathrm{mg} \mathrm{m}^{-2}$ c) $\Gamma>$ ca $1 \mathrm{mg} \mathrm{m}^{-2}$. Now, the interfacial diffusion for both polymers can be discussed regarding the morphology of the adsorbed polymers. The adsorbed polymer is characterized in the first regime either by floating "pancake"like morpholgies or by a self-similar adsorbed layer. With increasing surface concentration (around the first critical surface concentration $\Gamma_{1}$ ), the polymer chains at the interface interact significantly and the apparent diffusion coefficient $D_{\|}$might decrease. This decrease can be due to an increase either of the viscosity $\eta$ at the interface or the hydrodynamic radius $R_{h}$ of the polymer (which start to form loop and tails in the subphase). Both parameters affect the diffusion coefficient $\left(=k_{b} T / \zeta\right.$, where $k_{b} T$ is the thermal energy) as the friction coefficient $\zeta \sim \eta R_{h}$ increases.

In the intermediate surface concentration range $\left(0.4<\Gamma<\right.$ ca $\left.1 \mathrm{mg} \mathrm{m}^{-2}\right)$, a scaling law linking the interfacial diffusion coefficient to the surface concentration, $D_{\|} \sim \Gamma^{0.77}$ might be discussed. At about $\Gamma=0.4 \mathrm{mg} \mathrm{m}^{-2}$, the diblock copolymer adopts a 3D conformation with $\mathrm{PEO}$ chains extended into the water; this change 

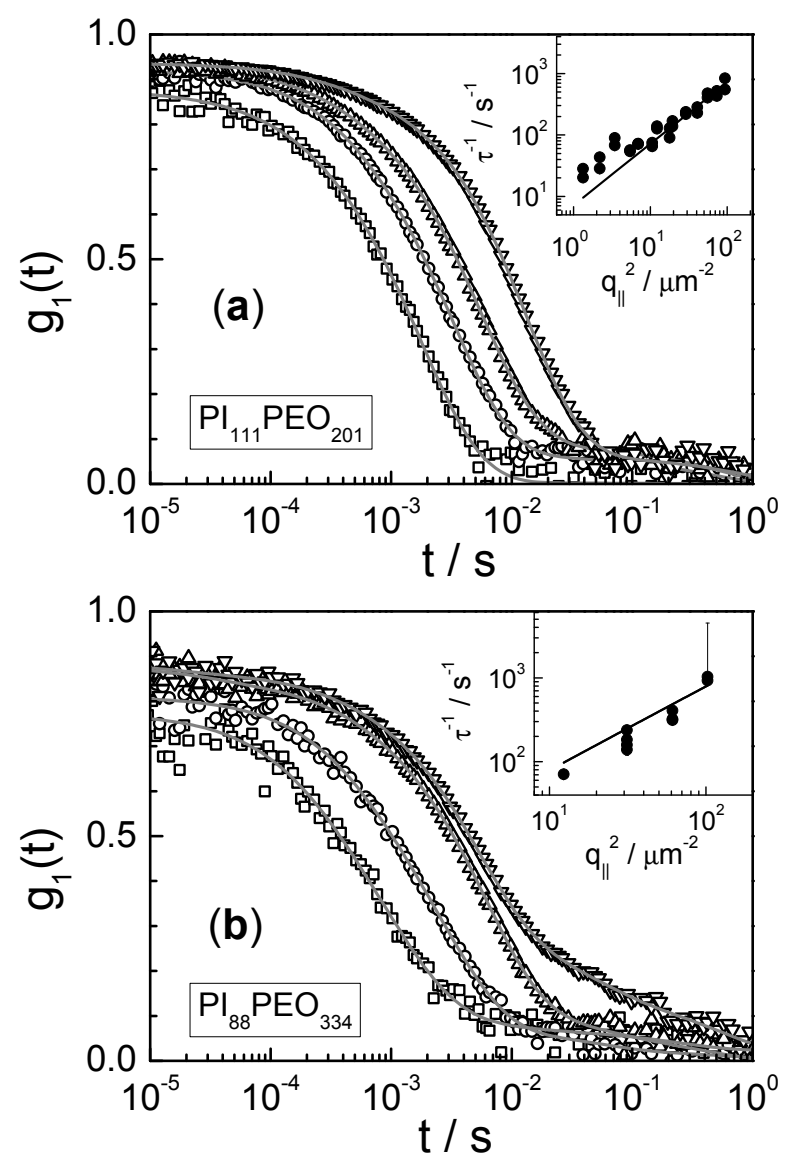

Figure 4: a) Field autocorrelation functions at $c=200 \mathrm{mg} \mathrm{L} \mathrm{L}^{-1}$ of $\mathrm{PI}_{111} \mathrm{PEO}_{201}$ for different $q_{\|}^{2}: 73 \mu \mathrm{m}^{-2}(\square), 41 \mu \mathrm{m}^{-2}(\circ), 19 \mu \mathrm{m}^{-2}(\triangle), 7 \mu \mathrm{m}^{-2}(\nabla)$. Inset: inverse of the relaxation time $\tau(\bullet)$ as a function of the square of the parallel component of the scattering vector $q_{\|}^{2}$. b) Field autocorrelation functions at $c=1.6 \mathrm{mg} \mathrm{L} \mathrm{L}^{-1}$ of $\mathrm{PI}_{88} \mathrm{PEO}_{334}$ for different $q_{\|}^{2}: 102 \mu \mathrm{m}^{-2}(\square), 61 \mu \mathrm{m}^{-2}(\circ), 31 \mu \mathrm{m}^{-2}(\triangle), 12 \mu \mathrm{m}^{-2}$ $(\nabla)$. Inset: $\tau^{-1}(\bullet)$ as a function of $q_{\|}^{2}$. Grey lines are the fitting curve of the autocorrelation functions. Black lines represent the fits $\tau^{-1}=D_{\|} q_{\|}^{2}$. 
is detected by a minimum of $D_{\|}$, corresponding to a maximum of $I_{s}$. For $\Gamma>0.4$ $\mathrm{mg} \mathrm{m} \mathrm{m}^{-2}\left(=\Gamma_{1}\right)$, the polymeric structure at the interface is relatively dense and the adsorbed chains interact. The consequence is a concerted motion relative to the air-water interface that can be detected by light scattering. This means that the apparent diffusion coefficient $D_{\|}$describes the cooperative diffusion of the polymeric structure relative to the solvent (in this case, the air-water interface). In this surface concentration range $D_{\|}$, in fact, shows the scaling of 0.77 characteristic of the cooperative diffusion predicted [2] and observed for diblock copolymer in solution [47]. Finally, for $\Gamma>$ ca $1 \mathrm{mg} \mathrm{m}{ }^{-2}$ a decreasing of $D_{\|}$was observed for $\mathrm{PI}_{111} \mathrm{PEO}_{201}$. This opposite behavior can be explained with the different relative importance of the hydrophilic and hydrophobic blocks structure. The shorter hydrophilic block allows an interaction of the PI blocks in the concentration range investigated. Thus, when the surface concentration becomes much larger than the coil overlapping, PI blocks of different chains interact and form larger aggregates or inter-chain entangled interfacial structures. These changes affect dramatically the interfacial friction and cause a decreasing of the diffusion coefficient $D_{\|}$.

\section{Conclusions}

The adsorption behavior of polyisoprene-poly(ethylene oxide) diblock copolymers at the air-water interface is governed by the hydrophobic and the hydrophilic block in specific ways. If the surface pressure is determined by the hydrophilic block PEO [13], the adsorption to and the anchorage at the interface is determined by the polyisoprene blocks over the whole concentration range. The relative size of the hydrophilic poly(ethylene oxide) block determines also the mode and intensity of interaction between the adsorbed hydrophobic blocks with increasing concentration. The latter result is clearly different from a previous investigation on PS-PEO copolymers (where PS is polystyrene), where the observed transition depends only on the size of PEO [13].

Interfacial equilibrium or pseudo-equilibrium adsorbed states were found mostly in a semidilute regime, where the polymer chains can protrude in the subphase but still do not form "brushes".

A transition from a two dimensional "pancake" or SSAL to a "mushroom" regime, in which polymer chains form loops and tails in the subphase, is observed with increasing surface concentration. From ellipsometric and surface pressure results this transition seems rather smooth but it can be clearly detected by the scattered intensity under evanescent illumination [14, 15]. Moreover, the apparent interfacial diffusion coefficient measured by evanescent wave dynamic light scattering shows the following scaling: $D_{\|} \sim \Gamma^{0.77}$ in analogy with the scaling observed for polymer molecules in the semidilute regime [2, 47]. 

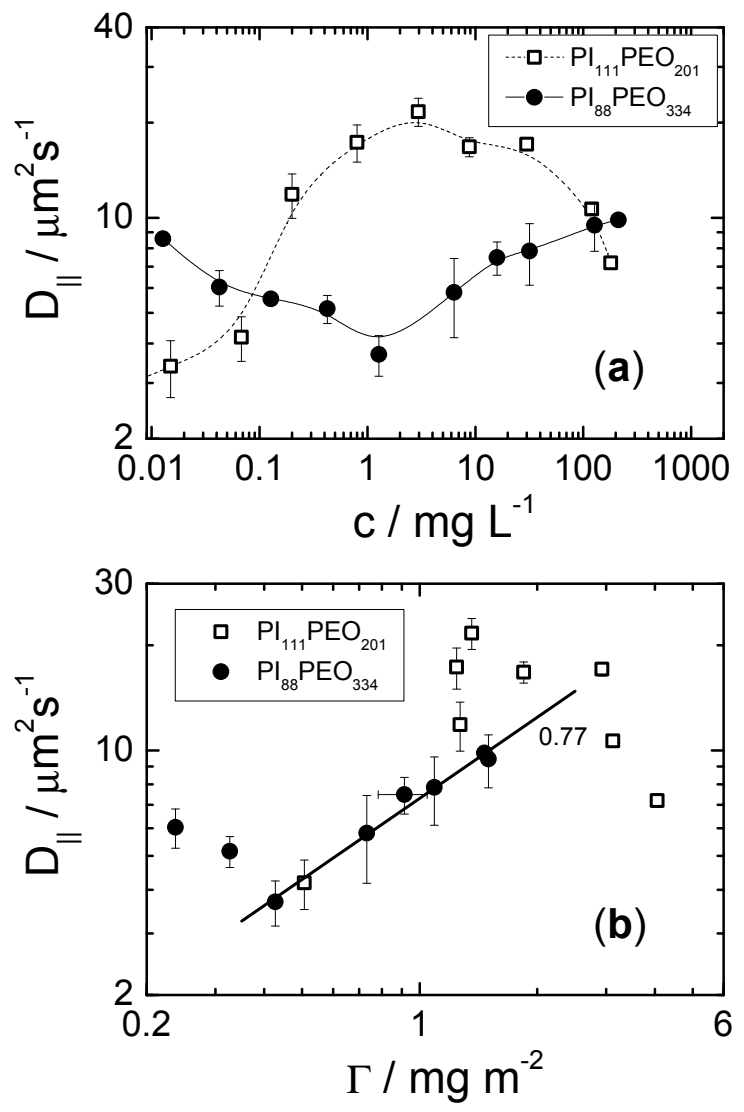

Figure 5: a) Diffusion constant calculated as $D_{\|}=\tau^{-1} q_{\|}^{-2}$ as a function of the polymer concentration for $\mathrm{PI}_{111} \mathrm{PEO}_{201}(\square)$ and $\mathrm{PI}_{88} \mathrm{PEO}_{334}(\bullet)$. Lines can be used to guide the viewers eyes. b) $D_{\|}$as a function of the surface concentration for $\mathrm{PI}_{111} \mathrm{PEO}_{201}(\square)$ and $\mathrm{PI}_{88} \mathrm{PEO}_{334}(\bullet)$. Solid line represents the scaling $D_{\|} \sim \Gamma^{0.77}$ 
At high surface concentrations, the decrease of the interfacial diffusion is discussed in terms of interactions and possible aggregation between the hydrophobic blocks which cause an increase of friction at the air-water interface.

In addition to previous investigations on similar systems (PEO-PPO-PEO and PSPEO copolymers), two new aspects have been found. First, we show that the scattered intensity $I_{s}$ and the apparent interfacial diffusion $D_{\|}$coefficient by evanescent wave light scattering provide new useful information to study interfacial phenomena. In fact, $I_{s}$ and $D_{\|}$can complement the information given by more standard methods such as surface pressure, surface rheology and ellipsometry.

Second, we described how relatively high molecular weight PI-PEO copolymers reorganize at the interface after successively adsorption from the bulk in presence of aggregates. From this perspective, this study can help understanding the exchange of polymer between aggregates in equilibrium or in kinetically frozen aggregates [38]. Finally, measuring the dynamics of polymers at the water surface remains an interesting topic towards the understanding of complex systems such as polypeptide and proteins at biological interfaces (e.g. lung airways).

\section{Acknowlegdements}

Financial support of the Max Planck Society is gratefully acknowledged.

\section{References}

[1] T.J. Joncheray, K.M. Denoncourt, M.A.R. Meier, U.S. Schubert, R.S. Duran, Langmuir 23 (2007) 2423.

[2] M. Doi, S. F. Edwards, The theory of polymer dynamics, Oxford science publications, 1986.

[3] M.K. Sanyal, V.V. Agrawal, M.K. Bera, K.P. Kalyanikutty, J. Daillant, C. Blot, S. Kubowicz, O. Konovalov, C.N.R. Rao, J. Phys. Chem. 112 (2008) 1739.

[4] M.G. Munoz, F. Monroy, F. Ortega, R.G. Rubio, D. Langevin, Langmuir 16 (2000) 1083.

[5] A.M. Diez-Pascual, A. Compostizo, A. Crespo-Colin, R.G. Rubio, R. Miller, J. Colloid Interface Sci. 307 (2007) 398.

[6] M.G. Munoz, F. Monroy, F. Ortega, R.G. Rubio, D. Langevin, Langmuir 16 (2000) 1094. 
[7] B.A. Noskov, A.V. Akentiev, D.O. Grigoriev, G. Loglio, R. Miller, J. Colloid Interface Sci. 282 (2005) 38.

[8] G. Rother, G.H. Findenegg , Colloid Polym. Sci. 276 (1998) 496.

[9] B. Rippner Blomqvist, T. Waernheim, P.M. Claesson, Langmuir 21 (2005) 6373.

[10] J.S. Phipps, R.M. Richardson, T. Cosgrove, A. Eaglesham, Langmuir 9 (1993) 3530 .

[11] C. Kim, H. Yu, Langmuir 19 (2003) 4460.

[12] P. Cicuta, I. Hopkinson, Europhysics Letters 68 (2004) 65.

[13] S. Rivillon, M.G. Munoz, F. Monroy, F. Ortega, R.G. Rubio, Macromolecules 36 (2003) 4068.

[14] B.A. Noskov, A.V. Akentiev, R. Miller, J. Colloid Interface Sci. 247 (2002) 117.

[15] B.A. Noskov, S.-Y. Lin, G. Loglio, R.G. Rubio, R. Miller, Langmuir 22 (2006) 2647.

[16] P. Cun Ke, C.A. Neumann, Langmuir 17 (2001) 5076.

[17] K. Ludtke, R. Jordan, N. Furr, S. Garg, K. Forsythe, C.A. Neumann, Langmuir 24 (2008) 5580.

[18] K.H. Lan, N. Ostrowsky, D. Sornette, Phys. Rev. Lett. 57 (1986) 17.

[19] B. Lin, S.A. Rice, D.A. Weitz, J. Chem. Phys. 10 (1993) 8308.

[20] R. Sigel, Curr. Opinion Colloid Interface Sci. 14 (2009) 426.

[21] P. G. de Gennes, Macromolecules 13 (1980) 1069.

[22] P. Alexandridis, T.A. Hatton, Colloids and Surf. A 96 (1995) 1.

[23] R. Sigel, S. Pispas, D. Vlassopoulos, N. Hadjichrisidis, G. Fytas, Macromolecules 32 (1999) 8447.

[24] F. Rittig, J. Karger, C.M. Papadakis, G. Fleischer, P. Stepanek, K. Almdal, Phys. Chem. Chem. Phys. 1 (1999) 3923.

[25] C.M. Papadakis, K. Almdal, K. Mortensen, F. Rittig, G. Fleischer, P. Stepanek, Eur. Phys. J. E 1 (2000) 275. 
[26] P. Holmqvist, S. Pispas, R. Sigel, N. Hadjichristidis, G. Fytas, D. Vlassopoulos, Macromolecules 35 (2002) 3157.

[27] P. Holmqvist, S. Pispas, N. Hadjichristidis, G. Fytas, R. Sigel, Macromolecules 36 (2003) 830.

[28] R. Sigel, S. Pispas, D. Vlassopoulos, N. Hadjichrisidis, G. Fytas, Phys. Rev. Lett. 83 (1999) 4666.

[29] B. Loppinet, R. Sigel, A. Larsen, G. Fytas, D. Vlassopoulos, G. Liu, Langmuir 16 (2000) 6480.

[30] S. Pispas, N. Hadjichristidis, Langmuir 19 (2003) 48.

[31] S. Pispas J. Polym. Sci. Part A: Polym. Chem. 44 (2006) 606.

[32] A. Stocco, T. Mokhtari, G. Haseloff, A. Erbe, R. Sigel, submitted to Phys. Rev. E.

[33] A. Stocco, K. Tauer, S. Pispas, R.Sigel, Eur. Phys. J. E 29 (2009) 95.

[34] A. Stocco and K. Tauer, Eur. Phys. J. E 30 (2009) 431.

[35] R.M.A. Azzam, N.M. Bazhara, Ellipsometry and polarized light, Elsevier: Amsterdam, 1977.

[36] J. Lekner, Theory of Reflection, Martinus Nijhoff Publishers, Dordrecht, 1987.

[37] G. Mountrichas, S. Pispas, A. Stocco, K. Tauer, R. Sigel, in preparation.

[38] T. Nicolai, O. Colombani, C. Chassenieux, Soft Matter 6 (2010) 3111.

[39] R. Toomey, J. Mays, M. Tirell, Macromolecules 37 (2004) 905.

[40] T.F. Svitova, M.J. Wetherbee, C.J. Radke, J. Colloid Interface Sci. 261 (2003) 170.

[41] Z.S. Gao, A. Eisenberg, Macromolecules 26 (1993) 7353.

[42] V. Aguie-Beghin, E. Leclerc, M. Deaoud, R. Douillard, J. Colloid Interface Sci. 214 (1999) 143.

[43] D. Langevin , Light Scattering by Liquid Surfaces and Complementary Techniques, Marcel Dekker, New York, 1992.

[44] P. Alexandridis, V. Athanassiou, S. Fukada, T.A. Hatton, Langmuir 10 (1994) 2604. 
[45] S. W. Provencher, Computer Physics Communications 3 (1982) 213.

[46] C. Ligoure, J.Phys II France 3(1993) 1607.

[47] T. Jian, S. H. Anastasiadis, A. N. Semenov, G. Fytas, K. Adachi, T. Kotaka, Macromolecules 27 (1994) 4762. 